Family Profile No. 21, 2017

\title{
Age Variation in the Remarriage Rate, 1990 \& 2015
}

Author: Huijing Wu

The remarriage rate in the U.S. has fallen dramatically over the past 20 years. In 1990, the remarriage rate was 50 per 1,000 previously marrieds (individuals divorced or widowed) versus 28 per 1,000 in 2015 (Figure 1). Although this represents roughly a $44 \%$ decline in the overall remarriage rate, the magnitude of the change over time varies considerably by age group. This profile updates FP-13-17 by combining data from the 1990 U.S. Vital Statistics and the 2015 American Community Survey to examine the change in the remarriage rate between 1990 and 2015 by age groups.

\section{Remarriage Rates}

Remarriage rates declined with age, although age variation was less pronounced in 2015 than 1990, reflecting convergence in the remarriage rate across age groups.

- $\quad$ The drop in the remarriage rate was largest at the youngest ages.

0 Among 20-24 year olds, the remarriage rate declined by 57\% from 237.5 (1990) to 101.1 (2015) per 1,000 previously marrieds.

o The remarriage rate fell by about $44 \%$ (from 171.9 to 97.0 per 1,000) among 25-34 year olds.

- At older ages, the remarriage rate has remained relatively stable over the past quarter century.

o The remarriage rate for those previously married aged 55-64 was 20.5 in 1990 compared to 19.0 in 2015.

0 Among the previously married aged 65 and older, the remarriage rate increased slightly from 4.6 in 1990 to 5.2 per 1,000 in 2015.

Figure 1. Remarriage Rates by Age Groups

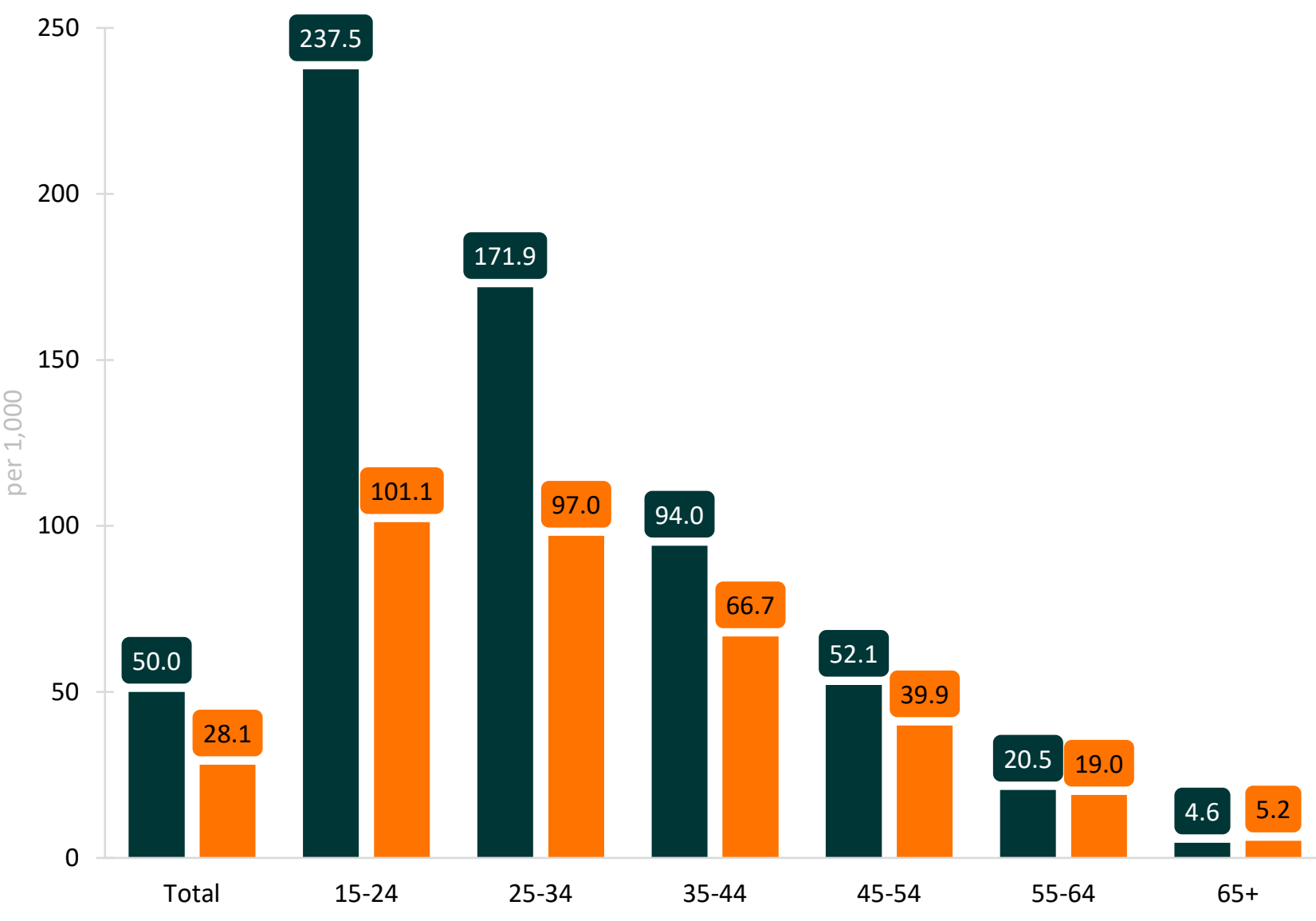




\section{Remarriage Rates by Gender}

The remarriage rate declined over time for both men and women, but the decrease was larger for men.

- In 1990 and 2015, men had higher remarriage rates than women at every age group beginning at 35. In 1990, men's remarriage rates exceed women's starting at age 25 .

- Among women, the remarriage rate declined for those under age 45 and increased slightly for those over 45 . For men, the remarriage rate declined over time for every age group.

- The gender gap in the remarriage rate has narrowed over the past 25 years for all age groups. The convergence was especially large for people aged 45-64.

o For men aged $45-54$, the remarriage rate fell $42 \%$ from 82.4 to 47.8 , whereas for women it remained essentially unchanged at 33.7 in 2015.

o Similarly, men aged 55-64 experienced a dramatic decline in their remarriage rate from 45.3 to 28.2 , yet women of the same age experienced a small increase from 10. 7 to 12.9.

Figure 2. Remarriage Rates by Age Groups and Gender, 1990

$$
\text { Men Women }
$$

250

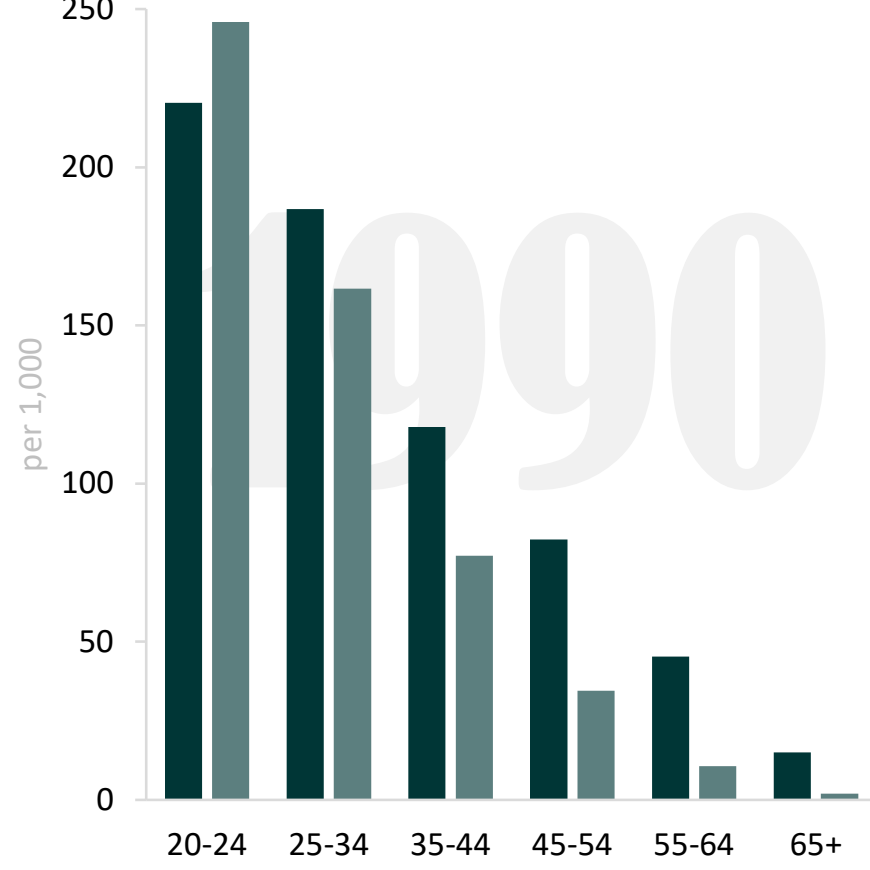

Figure 3. Remarriage Rates by Age Groups and Gender, 2015

$$
\text { Men Women }
$$

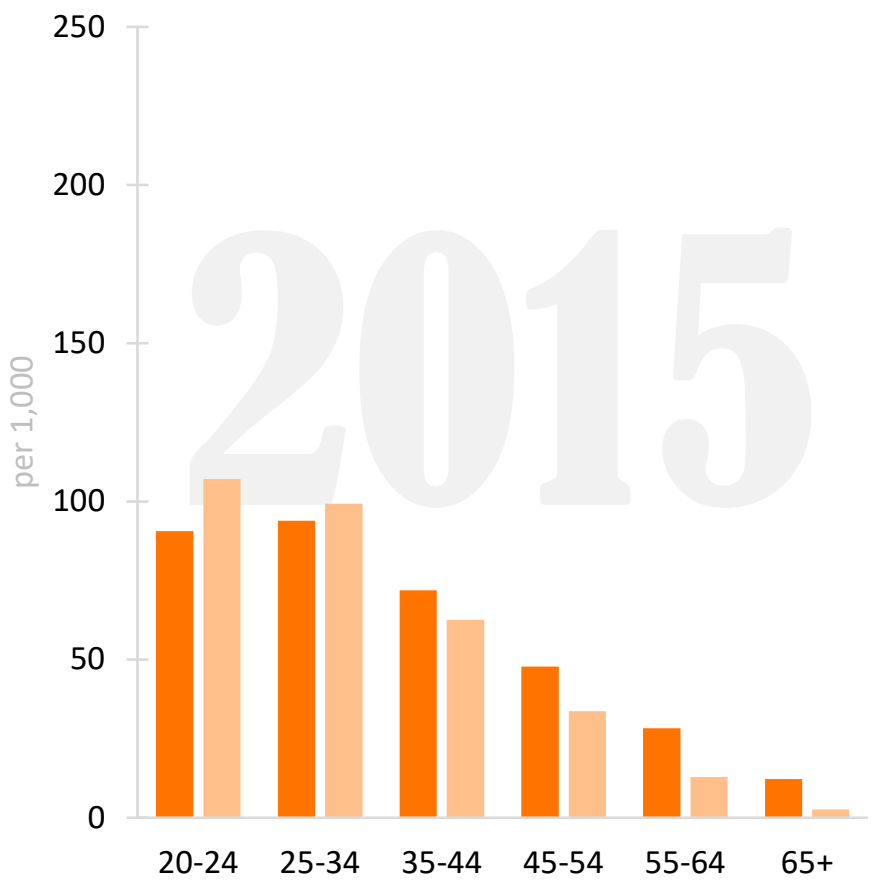

Source: NCFMR analyses of Centers for Disease Control and Prevention, National Center for Health Statistics, Vital Stats and U.S. Census Bureau, American Community Survey, 2015

\section{References:}

Brown, S. L. \& Lin, 1.-F. (2013). Age variation in the remarriage rate, 1990-2011. Family Profiles, FP-13-17. Bowling Green, OH: National Center for Family \& Marriage Research. http ://www. bgsu. ed u/contenUdam/BGSU/col lege-of-arts-and-sciences/NC FM R/docu ments/FP /F P-13-1 7 .pdf.

\section{Suggested Citation:}

Wu, H. (2017). Age variation in the remarriage rate, 1990-2015. Family Profiles, FP-17-21. Bowling Green, OH: National Center for Family \& Marriage Research. https://doi.org/10.25035/ncfmr/fp-17-21

RSO. National Center for

BCSU. Family \& Marriage Research

BOWLING GREEN STATE UNIVERSITY http://www.bgsu.edu/ncfmr

ncfmr@bgsu.edu

(419) 372-3119

This project is supported with assistance from Bowling Green State University. From 2007 to 2013, support was also provided by the U.S. Department of Health and Human Services, Office of the Assistant Secretary for Planning and Evaluation. The opinions and conclusions expressed herein are solely those of the author(s) and should not be construed as representing the opinions or policy of any agency of the state or federal government. 